\title{
Syndrome of inappropriate secretion of antidiuretic hormone (SIADH) associated with lateral medullary syndrome: case report and literature review
}

\author{
Hiroro Nakano ${ }^{1,2^{*}}$, Daisuke Yanase ${ }^{1}$ and Masahito Yamada ${ }^{2}$
}

\begin{abstract}
Background: Only one case of syndrome of inappropriate secretion of antidiuretic hormone with lateral medullary syndrome has been reported so far. We report a case of lateral medullary syndrome showing syndrome of inappropriate secretion of antidiuretic hormone and analyze the pathomechanism underlying its clinical features.

Case presentation: A 67-year-old man was admitted to our hospital for dizziness, dysarthria, and dysphagia. He was diagnosed with lateral medullary syndrome based on the neurological examination and brain magnetic resonance imaging. Horner syndrome was absent. Asymptomatic hyponatremia appeared 9 days after admission and the patient was diagnosed with syndrome of inappropriate secretion of antidiuretic hormone. Fluid restriction and intravenous furosemide injection improved the hyponatremia.
\end{abstract}

Conclusion: Lateral medullary syndrome could be associated with syndrome of inappropriate secretion of antidiuretic hormone.

Keywords: Syndrome of inappropriate secretion of antidiuretic hormone, Lateral medullary syndrome, Antidiuretic hormone, The nucleus of the solitary tract, The paraventricular nucleus in the hypothalamus

\section{Background}

Hyponatremia, defined as condition in which serum sodium is $<135 \mathrm{mEq} / \mathrm{L}$, is the most common electrolyte abnormality encountered worldwide [1]. One of the major causes of hyponatremia is syndrome of inappropriate secretion of antidiuretic hormone (SIADH), which is caused by various conditions such as malignancies, pulmonary disorders, medications, and acute central nervous system diseases [2]. A previous study reported hyponatremia in nearly $13.8 \%$ of more than 8,500 cases of stroke patients [3]. However, only one case of SIADH with lateral medullary syndrome has been reported so far [4]. In this report, we present SIADH in a patient with lateral medullary syndrome and discuss the pathomechanism of SIADH.

\footnotetext{
* Correspondence: neuro-nakano@med.kanazawa-u.ac.jp

'Department of Neurology, Kouseiren Takaoka Hospital, Takaoka, Japan

${ }^{2}$ Department of Neurology and Neurobiology of Aging, Kanazawa University Graduate School of Medical Sciences, 13-1 Takara-machi, Kanazawa 920-8640, Japan
}

\section{Case presentation} he was fully conscious, and the physical examination was almost normal except for hypertension and tachycardia in a regular rhythm. Neurological examination revealed equal and round pupils with a normal light reflex. His extraocular movements were full range without diplopia, but he showed gaze-evoked horizontal nystagmus, dysarthria, and dysphagia. He had no complaint of dysgeusia. Muscle tonus was normal without obvious paralysis in all four limbs. Examination of the sensory system revealed hypothermia and hypoalgesia with normal tactile sensation over the left side of his face and right half of his trunk and limbs. Vibration and position sensation were normal in all four limbs. He presented with ataxia in his left upper and lower limbs. Tendon reflexes were normal in his upper limbs and absent in his 
lower limbs without the extensor plantar reflex. Brain magnetic resonance imaging (MRI) demonstrated hyperintensity in the left side of the dorsolateral medulla with diffusion weighted imaging (DWI) with hypointensity on apparent diffusion coefficient (ADC)-map (Fig. 1). He was diagnosed as having lateral medullary syndrome and was treated with oral clopidogrel (continued during admission), intravenous argatroban for 3 days, edaravone for 9 days, and hydration with normal saline $(1.5 \mathrm{~L} /$ day $)$.

Hematological examination showed normal serum sodium levels of $139 \mathrm{mEq} / \mathrm{L}$ on admission, however, the serum sodium levels decreased gradually, and 9 days after admission (13 days after onset), he developed asymptomatic hyponatremia $(109 \mathrm{mEq} / \mathrm{L})$ with a decreased serum osmolarity of $223 \mathrm{mOsm} / \mathrm{L}$ (normal range, $275-295 \mathrm{mOsm} / \mathrm{L}$ ). The turgor in all four limbs was normal, and he did not present with obvious thirst. Thyroid, renal, and adrenal functions were normal, but increased serum levels of antidiuretic hormone $(\mathrm{ADH})$ (6.9 pg/mL; normal range, $0.3-4.2 \mathrm{pg} / \mathrm{mL}$ ) were observed. Urine osmolarity was $668 \mathrm{mOsm} / \mathrm{kgH}_{2} \mathrm{O}$ (normal range, $100-1,300 \mathrm{mOsm} / \mathrm{kgH}_{2} \mathrm{O}$ ), and urine sodium was $121 \mathrm{mOsm} / \mathrm{L}$ (normal range, 40 $90 \mathrm{mOsm} / \mathrm{L}$ ). Thoracoabdominal CT images showed no abnormalities, such as mass lesions or lymphadenopathy. He was diagnosed as having SIADH based on the diagnostic criteria of Bartter and Schwartz [5]. He was treated with fluid restriction and intravenous furosemide injections.

Laboratory examination on the 23rd day after admission showed almost normal serum sodium levels $(136 \mathrm{mEq} / \mathrm{L})$ with normal serum ADH levels $(1.2 \mathrm{pg} / \mathrm{mL})$. His neurological symptoms, such as dizziness and dysarthria, also gradually resolved, and thereafter, hyponatremia was not observed.

\section{Conclusion}

Our patient with lateral medullary syndrome showed asymptomatic hyponatremia 13 days after the onset of lateral medullary syndrome. With the exclusion of other causes of hyponatremia, we diagnosed the hyponatremia as SIADH. It has been reported that SIADH is difficult to distinguish from cerebral salt wasting syndrome, another cause of hyponatremia characterized by renal loss of sodium and decreases in extracellular fluid volume during intracranial disorders [6]; nonetheless, the abnormal ADH secretion and lack of clinical symptoms of dehydration in our patient were consistent with the characteristics of SIADH [7], although precise evaluation of the volemic state has been considered difficult [8]. Thoracoabdominal CT images indicated no evidence of ectopic ADH producing tumors. Nine days after admission, the serum sodium levels gradually improved. After the primary treatment for SIADH, our patient presented almost normal serum sodium levels with resolution of his neurological symptoms, and thereafter, he showed no relapse of hyponatremia, indicating that SIADH could be closely related to ischemic damage in the dorsolateral medulla. As edaravone was administered for 9 days after admission, the possibility that edaravone contributed to the pathophysiology of SIADH cannot be ruled out, although no case of SIADH associated with edaravone has been reported so far.

In retrograde tracing studies, two major neural pathways were identified between the dorsolateral medullary area and the hypothalamus $[9,10]$. These include (1) the sympathetic descending tract and (2) the interacting neural pathway between the paraventricular nucleus in the hypothalamus (PVH) and the nucleus of the solitary tract (NTS), although the neurological function of the later pathway is not understood yet. The NTS could be

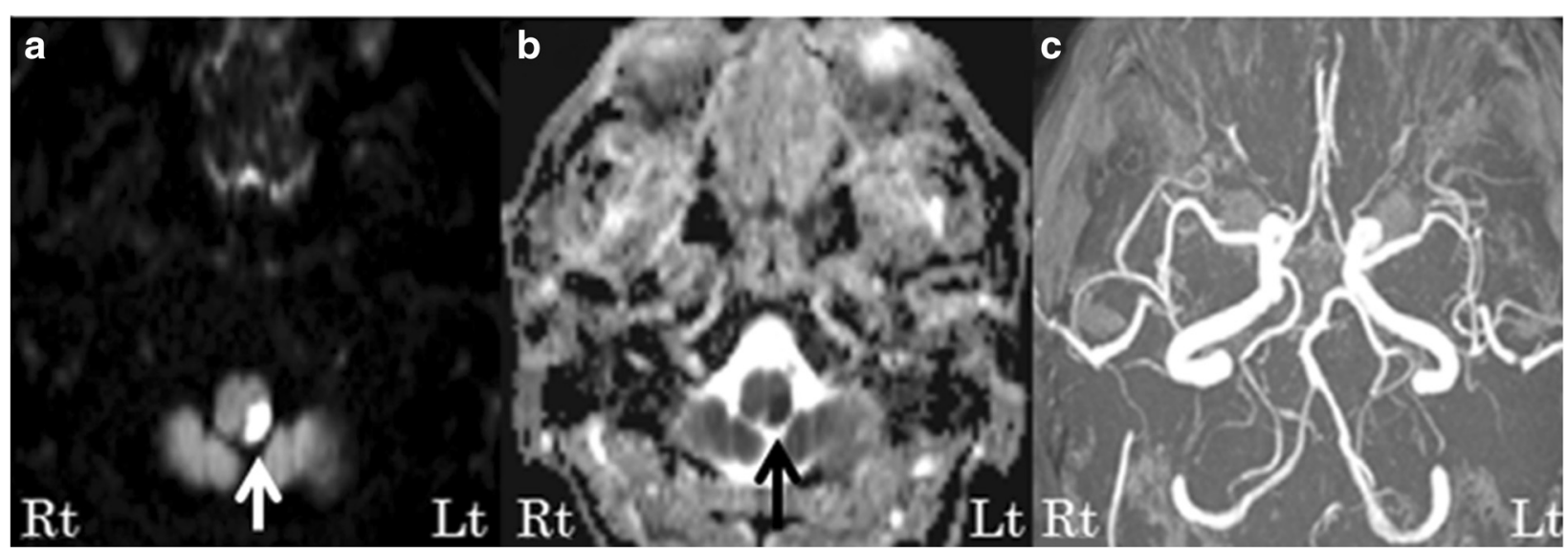

Fig. 1 Magnetic resonance imaging (MRI) and MR angiography findings. a, b Diffusion-weighted magnetic resonance imaging (DWI) showed the hyperintensity in the left dorsolateral medulla (a, white arrow) with hypointensity on apparent diffusion coefficient (ADC)-map (b, black arrow). $\mathbf{c}$ MR angiography demonstrated no obvious occlusion 
Table 1 Clinical features of SIADH in patients with Wallenberg syndrome $[4,11,12]$

\begin{tabular}{|c|c|c|c|}
\hline & This case & Previous case [4] & Typical features [11, 12] \\
\hline \multirow[t]{2}{*}{ Age(y.o.)/Sex } & \multirow[t]{2}{*}{ 67/Male } & \multirow[t]{2}{*}{ 44/Male } & mean age: $57 \pm 11.9$ \\
\hline & & & Male: Female $=2.25: 1$ \\
\hline Initial symptoms & dizziness, dysarthria, dysphagia & $\begin{array}{l}\text { headache, dysphagia, } \\
\text { hiccups, }\end{array}$ & $\begin{array}{l}\text { dizziness, vertigo, gait ataxia, } \\
\text { dysarthria, dysphagia }\end{array}$ \\
\hline Neurological symptoms & $\begin{array}{l}\text { crossed sensory disturbance, } \\
\text { cerebellar ataxia, nystagmus }\end{array}$ & $\begin{array}{l}\text { crossed sensory disturbance, } \\
\text { cerebellar ataxia }\end{array}$ & $\begin{array}{l}\text { crossed sensory disturbance, } \\
\text { cerebellar ataxia }\end{array}$ \\
\hline Horner syndrome & - & + & + \\
\hline Dysgeusia & - & - & occasionally observed \\
\hline Past history & diabetes mellitus & not described & $\begin{array}{l}\text { hypertension, diabetes mellitus, } \\
\text { cigarette smoking }\end{array}$ \\
\hline Treatment for cerebral infarction & edaravone oral clopidogrel argatroban & edaravone & varies depend on the causes \\
\hline $\begin{array}{l}\text { Interval days between the onset of } \\
\text { Wallenberg syndrome and hyponatremia }\end{array}$ & thirteen days & fifteen days & \\
\hline Symptom of hyponatremia & asymptomatic & asymptomatic & \\
\hline Treatment for hyponetremia & $\begin{array}{l}\text { restriction of fluid intake, intravenous } \\
\text { furosemide }\end{array}$ & restriction of fluid intake & \\
\hline Clinical course & improved & improved & \\
\hline
\end{tabular}

involved in the mechanism of SIADH in lateral medullary syndrome, as discussed in the previously reported case [4]. However, as the NTS is occasionally involved in lateral medullary syndrome [11], the ischemic damage of the NTS cannot simply explain the pathogenesis of SIADH in lateral medullary syndrome. Although SIADH in our patient would be related to the exaggerated ADH response to ischemic damage as discussed in the previously reported [12], we speculated that the ischemic damage of the ascending neural pathway from the NTS to the $\mathrm{PVH}$ could be related to the pathogenesis of SIADH in lateral medullary syndrome.

We analyzed the clinical findings on lateral medullary syndrome and SIADH, from our patient and the previously reported one [4], and compared them with the typical features of lateral medullary syndrome $[13,14]$ (Table 1$)$. The three clinical symptoms, including (1) crossed sensory disturbance, (2) bulbar palsy, and (3) cerebellar ataxia, are considered the main symptoms of lateral medullary syndrome $[13,14]$, and both patients showed these typical symptoms. Interestingly, asymptomatic hyponatremia was identified at 13 days in our patient and at 15 days in the previously reported patient after the onset of lateral medullary syndrome. The main difference in the clinical features between our patient and the previously reported one was the presence of Horner syndrome. The absence of Horner syndrome in our patient indicated that the sympathetic descending tract was spared from severe ischemic damages, and the sympathetic descending tract would be anatomically separated from the ascending neural pathway from the NTS to PVH. Both patients presented no sign of dysgeusia, suggesting that the NTS was spared from severe ischemic damages, although the MRI findings in both patients were similar to those of typical lateral medullary syndrome [14]. The ascending neural pathway from the NTS to PVH may be associated with ADH secretion, and this pathway may be less involved in most patients with lateral medullary syndrome, however, the ascending neural pathway could be more involved in the clinical manifestations observed in our patient and the previously reported one [4]. It is suggested that the minority of patients with lateral medullary syndrome would present with damage of the ascending neural pathway from the NTS to PVH.

We described SIADH in a patient with lateral medullary syndrome. Taken together with the previously reported case, we suggest that lateral medullary syndrome could be associated with hyponatremia.

\section{Abbreviations}

ADC, apparent diffusion coefficient; ADH, antidiuretic hormone; DWI, diffusion weighted imaging; NTS, the nucleus of the solitary tract; $P V H$, the paraventricular nucleus in the hypothalamus; SIADH, syndrome of inappropriate secretion of antidiuretic hormone

\section{Acknowledgements}

None.

\section{Funding}

We receive no funding support.

\section{Availability of data and materials}

The datasets supporting the conclusions of this article are included within the article.

\section{Authors' contributions}

Study concept and design: HN, DY. Analysis and interpretation of data: HN, DY, MY. Drafting of the manuscript: HN, DY. Critical revision of the manuscript for important intellectual content: HN, DY, MY. All authors have read and approved the final manuscript.

Competing interests

The authors declare that they have no competing interests. 


\section{Consent for publication}

We obtained written informed consent from the patient for publication of this case report, and any accompanying images. A copy of the written consent is available for review by the Editor of this journal.

\section{Ethics approval and consent to participate}

Not applicable.

Received: 10 April 2016 Accepted: 20 July 2016

Published online: 27 July 2016

\section{References}

1. Kirkman MA, Albert AF, Ibrahim A, Doberenz D. Hyponatremia and brain injury: historical and contemporary perspectives. Neurocrit Care. 2013:18:406-16.

2. Hannon MJ, Thompson CJ. The syndrome of inappropriate antidiuretic hormone: prevalence, causes and consequences. Eur J Endocrinol. 2010; 162:S5-12.

3. Soiza RL, Cumming K, Clark AB, Bettencourt-Silva JH, Metcalf AK, Bowles KM, et al. Hyponatremia predicts mortality after stroke. Int J Stroke. 2015;10:50-5.

4. Nomoto $\mathrm{N}$, Konno S, Sugimoto $\mathrm{H}$, Kurihara T, Wakata N. Wallenberg syndrome with SIADH. Eur Neurol. 2005;53:35-6.

5. Bartter FC, Schwartz WB. The syndrome of inappropriate secretion of antidiuretic hormone. Am J Med. 1967;42:790-806.

6. Ellison DH, Berl T. Clinical practice. The syndrome of inappropriate antidiuresis. N Engl J Med. 2007;356:2064-72.

7. Cerdà-Esteve M, Cuadrado-Godia E, Chillaron JJ, Pont-Sunyer C, Cucurella G, Fernández $M$, et al. Cerebral salt wasting syndrome: review. Eur J Intern Med. 2008;19:249-54.

8. George JT, Warriner D, McGrane DJ, Rozario KS, Price HC, Wilmot EG, et al. Lack of confidence among trainee doctors in the management of diabetes: the Trainees Own Perception of Delivery of Care (TOPDOC) Diabetes Study. QJM. 2011;104:761-6.

9. Affleck VS, Coote JH, Pyner S. The projection and synaptic organisation of NTS afferent connections with presympathetic neurons, GABA and nNOS neurons in the paraventricular nucleus of the hypothalamus. Neuroscience. 2012;219:48-61.

10. Hosoya Y, Sugiura Y, Okado N, Loewy AD, Kohno K. Descending input from the hypothalamic paraventricular nucleus to sympathetic preganglionic neurons in the rat. Exp Brain Res. 1991;85:10-20.

11. Day GS, Swartz RH, Chenkin J, Shamji Al, Frost DW. Lateral medullary syndrome: a diagnostic approach illustrated through case presentation and literature review. CJEM. 2014;16:164-70.

12. Esposito P, Piotti G, Bianzina S, Malul Y, Dal Canton A. The syndrome of inappropriate antidiuresis: pathophysiology, clinical management and new therapeutic options. Nephron Clin Pract. 2011;119:62-73.

13. Kato S, Takikawa M, Ishihara S, Yokoyama A, Kato M. Pathologic reappraisal of wallenberg syndrome: a pathologic distribution study and analysis of literature. Yonago Acta Med. 2014;57:1-14.

14. Kim JS. Pure lateral medullary infarction: clinical-radiological correlation of 130 acute, consecutive patients. Brain. 2003;126:1864-72.

\section{Submit your next manuscript to BioMed Central and we will help you at every step:}

- We accept pre-submission inquiries

- Our selector tool helps you to find the most relevant journal

- We provide round the clock customer support

- Convenient online submission

- Thorough peer review

- Inclusion in PubMed and all major indexing services

- Maximum visibility for your research

Submit your manuscript at www.biomedcentral.com/submit 